\title{
Territorio comunal: acuerdos locales para el aprovechamiento del bosque en la comunidad indígena de San Juan Pamatácuaro, México
}

\author{
Communal Territory: Local Agreements for Forest \\ Exploitation in the Indigenous Community of San Juan \\ Pamatácuaro, Mexico
}

\author{
Rigoberto Sandoval-Contreras ${ }^{1}$ \\ Universidad de Guadalajara, México
}

\begin{abstract}
Resumen
Este artículo aborda los acuerdos locales que norman y regulan el aprovechamiento del bosque en la comunidad indígena de San Juan Pamatácuaro en el Estado de Michoacán México, el cual goza de un territorio prácticamente cubierto de bosque templado, mismo que está dividido en dos extensiones: las parcelas y el área de uso común. Cabe decir, que hay escasos espacios destinados al uso agrícola. Los comuneros tienen derecho a una parcela para la extracción de madera y así obtener ingresos para el sustento de la familia, es parte de los acuerdos que se conforman a partir de un sistema normativo de usos y costumbres que determinan la organización del territorio y de la comunidad en aspectos como: la familia, el trabajo maderero, proyectos productivos, entre otros. El trabajo de campo y observaciones desde marco conceptual fortaleció el análisis y desarrollo de la investigación.
\end{abstract}

Palabras clave: Territorio comunal, bosque templado, acuerdos locales, sistema normativo de usos y costumbres.

1 Dr. en Ciencias Sociales en el Área de Estudios Rurales, Departamento de Ciencias Sociales y Humanidades Universidad de Guadalajara, Centro Universitario de los Valles Carretera Guadalajara-Ameca Km. 45.5 46600 Ameca, Jalisco. Correo electrónico: rigoberto.sandoval@valles.udg.mx 


\begin{abstract}
This article discusses the local agreements that rule and regulate the exploitation of forests in the indigenous community of San Juan Pamatacuaro, state of Michoacan, Mexico. This community enjoys a territory practically covered of a temperate forest, which is divided into two extensions: the plots of land and the area of common use. It is worth mentioning that there are few spaces intended for agricultural use. Community members have the right to a plot for the extraction of timber and so to earn income for the sustenance of the family: this is part of the agreements that make up from a normative system of uses and customs that determine the organization of the territory and the community in aspects such as family, timber work, productive projects, among others. The field work and observations from conceptual framework strengthened the analysis and development of research.
\end{abstract}

Keywords: Community territory, temperate forest, local agreements, normative system of uses and customs.

\title{
Introducción
}

San Juan Pamatácuaro es una comunidad indígena que se localiza, prácticamente en el corazón de la Sierra Tarasca, en el Estado de Michoacán, México (Mapa. 1). Para los que no vivimos ahí, radicar en la comunidad puede producir la sensación de que se está aislado en un territorio montañoso y boscoso. Al permanecer un tiempo en el pueblo todo parece estar funcionando perfectamente: la organización de su entorno familiar, sus actividades madereras, comida típica, fiestas patronales y otras tradiciones. Al conocer la gente, costumbres y autoridades podemos descubrir que la vida transcurre bajo la funcionalidad de instituciones que se fundamentan como sistema normativo local, que determinan la organización social, la convivencia y la interrelación con su territorio cubierto en su mayoría de bosque templado. A pesar de que sus pobladores tienen vínculos con el exterior: comercial, migratorio, entre otras actividades. 
Rigoberto Sandoval-Contreras. Territorio comunal: acuerdos locales para el aprovechamiento del bosque en la comunidad indígena de San Juan Pamatácuaro, México

Mapa 1. Ubicación de San Juan Nuevo, Mich., México.

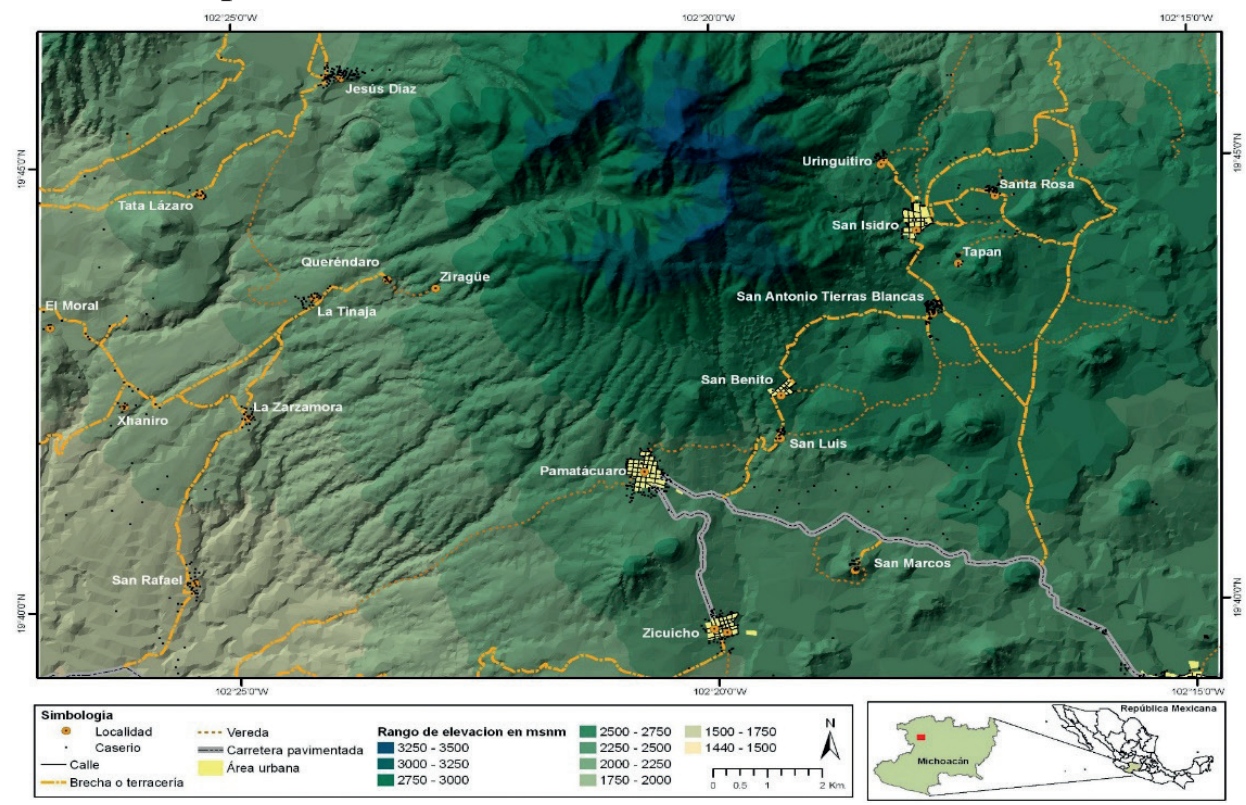

La interrelación del bosque templado y sus apropiadores (comuneros), se basa en lo que hemos encontrado y nombrado como acuerdos locales, estos se constituyen como una institución comunitaria que regula su uso y explotación. Se construye socialmente debido al uso y manejo que los habitantes de San Juan Pamatácuaro están haciendo de él. Se ha vuelto un elemento normado y regulado por sus usos y costumbres, como parte de su propia cultura y en sus propias particularidades ${ }^{2}$.

El uso de su bosque se rige por un mecanismo de orden social que funciona como institución, así como lo sugiere Ostrom (2000), ya que regula el comportamiento de los comuneros para su explotación ${ }^{3}$. Este sistema normativo-acuerdos locales- son aplicables a todos los miembros de la comunidad; consiste en acuerdos que no se encuentran escritos en ninguna parte, pero en la práctica diaria han sido aprobadas las maneras de proceder, usar, explotar, apropiar el bosque y su contenido (hongos,

2 Mari Jose-Amerlinck y Fernando Bontempo (1994:12-14), desde la antropología, la cultura es lo que hace diferente a un grupo social de otros.

3 Ostrom (2000) define institución como un sistema de reglas y normas que los individuos crean para el uso y manejo de sus recursos naturales. 
leña, diferentes hiervas comestibles). Una forma peculiar de usar y aprovechar sus recursos.

\section{Metodología}

Este trabajo parte de una perspectiva sociológica y etnográfica para analizar y explicar cómo se están utilizando los recursos forestales en una comunidad indígena, San Juan Pamatácuaro, México. Se realizaron quince entrevistas a los artesanos, así como a las autoridades comunales (seis integrantes) y algunos profesionistas (seis). Las preguntas que guiaron el diálogo fueron: ¿Quiénes son comuneros? ¿Cómo se ha parcelado el bosque? ¿Quiénes tienen derecho a las parcelas? ¿Cómo se hereda la parcela? ¿Cómo se usa el área de uso común? ¿Cómo se regula la extracción de la madera? ¿Cómo se dan los acuerdos para la explotación del bosque en la comunidad? Se hicieron recorridos por el bosque para identificar la delimitación parcelar y el área de uso común. Se permaneció durante un poco más de seis meses en la comunidad y después se hicieron visitas esporádicas durante 5 años, durante el periodo de estudios de maestría y doctorado. Lo anterior facilitó conocer en detalles qué sucede en la comunidad indígena de San Juan Nuevo respecto al uso de sus recursos forestales.

El trabajo de campo ayudó a conocer cómo está organizada la comunidad para aprovechar el bosque, cómo se usa, quiénes lo usan, cómo se heredan las parcelas, qué dice la ley forestal con la realidad observada, la relación que hay entre los sistemas de cargos y el bosque, cómo es la comunidad agraria y cómo son los acuerdos locales de la comunidad para aprovechar el bosque templado. El marco teórico utilizado ayudó a enmarcar las observaciones en campo, poniendo atención en ciertos aspectos, facilitando la presentación de resultados en los apartados que a continuación se desarrollan.

\section{Marco teórico-conceptual}

Para el análisis se retomó la propuesta teórica de Ostrom (2000) y Elster (1995). De la primera, se consideró el concepto de institución, ya que, se reconoce la capacidad que tienen los miembros de una comunidad de diseñar normas y reglas, para usar sus recursos; también se utilizaron otros conceptos como los de linderos definidos, congruencia, monitoreo y supervisión, entre otros, para reflexionar sobre la temática estudiada. Del 
Rigoberto Sandoval-Contreras. Territorio comunal: acuerdos locales para el aprovechamiento del bosque en la comunidad indígena de San Juan Pamatácuaro, México

segundo, se refuerza la idea que las instituciones son normas adquiridas en la socialización del sujeto, haciendo ver que sí impactan en sus acciones, no obstante, sus decisiones no son mecánicas, sino que resultan de una valoración previa para decidir. Ambas posturas ayudaron a enmarcar la observación en campo para la producción de datos y describir lo que está sucediendo con el recurso forestal.

Para hablar de la configuración del territorio comunal y el aprovechamiento del bosque en San Juan Pamatácuaro, es necesario hablar de la organización socioterritorial del municipio: lo ideal y lo real de la explotación del bosque; los sistemas de cargos y el bosque; la comunidad agraria como organización social, así como de los acuerdos locales existentes que determinan el uso del bosque, los cuales se fundamentan en las "otras" leyes no escritas que regulan las acciones de los comuneros para proceder en la división y apropiación del mismo.

\section{Municipio: lo ideal y lo real de la explotación del bosque}

Una primera forma de organización social territorial es que la comunidad agraria de San Juan Pamatácuaro, está ubicada dentro del Municipio de Los Reyes. Éste se relaciona con la comunidad como administración política y lindero territorial, en tanto que, de ahí se destinan programas de infraestructura, se eligen representantes municipales y se reconoce legalmente el territorio comunal. Sin embargo, no mantiene alguna relación de monitoreo o supervisión de cómo se está usando el bosque en la comunidad. Está demostrado que el municipio puede tener incidencia significativa en la implementación de programas, proyectos productivos, diseño de estrategias, recopilación de datos útiles para los programas de desarrollo, así como establecer vínculos con organismos nacionales y estatales, entre otros (Altschuler, 2008).

En este caso, el municipio no impulsa campañas de reforestación y las secretarías no han mantenido vínculos constantes, dado que la comunidad de Pamatácuaro carece de permisos legales para hacer una extracción del recurso maderero al no contar con un programa de manejo vigente autorizado por la Secretaría de Medio Ambiente y Recursos Naturales (SEMARNAT) y Procuraduría Federal del Medio Ambiente (PROFEPA), bajo los lineamientos de la Ley General de Desarrollo Forestal Sustentable (2003) (Véase Art. 3 Fracc. III, IV, VIII, XI, XXV; 
Art.7, XVIII; Art. 13 sec.3; Título $3^{\circ}$ cap. I; Art.55 Fracc.V, Título Cuarto Cap.I). En México los municipios no tienen la potestad de regular el uso y manejo de recursos forestales.

La Ley Forestal (2003) deroga las concesiones forestales y dicta reglas para el diseño de planes de manejo encaminados a la sustentabilidad de los bosques, también está permitido que los ejidatarios y/o comuneros contraten servicios técnicos para su aprovechamiento. En este precedente se habla de un desarrollo sustentable del bosque como un proyecto social y político que apunta hacia la descentralización y el ordenamiento ecológico que debiera partir de la participación directa de las comunidades dueñas del recurso (Rodríguez y Cruz, 2012; Samper, 2013; Cernea, 1995; Leff, 1995). Sin embargo, es pertinente resaltar la distancia que existe entre lo ideal y lo real, de cómo se aprovecha el bosque en territorio mexicano. Por un lado, existen leyes oficiales que norman para que no se deteriore y se conserve para las generaciones futuras. Por otro lado, la realidad en varios ejidos y comunidades de México no se ajusta al contenido de leyes oficiales, como en el territorio comunal de San Juan Pamatácuaro, Michoacán.

En varias partes del territorio mexicano los núcleos agrarios con bosques los están aprovechando en base a sus propios acuerdos locales, como el caso que presenta Martín (2001) en la reserva de la biósfera de la mariposa monarca en otra parte del territorio michoacano, quien reconoce, que aparentemente se hace un aprovechamiento de recursos acorde a la ley forestal, pero no es así. Se evidencia una contradicción entre lo ideal que marcan las leyes mexicanas para regular el uso del bosque y lo real de cómo es el uso verdaderamente.

Cabe decir que a partir del año 2000 en México existen programas federales que destinan recursos económicos para la conservación de los recursos forestales de manera planificada: Programa de Desarrollo Forestal (PRODEFOR) y el Proyecto de Conservación y Manejo Sustentable de los Recursos Forestales (PROCYMAT). Al parecer hay un reconocimiento para México, debido a que las superficies forestales que contienen extensa biodiversidad se encuentran bajo tenencia ejidal o de comunidades indígenas con un $60 \%$ (The Nature Conservancy, 2007), se considera que dicha modalidad facilita el manejo colectivo de los recursos forestales y que al estar involucrados los dueños de éstos se conservan, la gente aprende a hacer un manejo adecuado, se crea cultura, se reducen costos y se obtienen 
Rigoberto Sandoval-Contreras. Territorio comunal: acuerdos locales para el aprovechamiento del bosque en la comunidad indígena de San Juan Pamatácuaro, México

beneficios económicos. Sin embargo, estos programas no han sido canalizados por vía municipal o por autoridades locales a Pamatácuaro (representante de bienes comunales), ello muestra que lo ideal de un programa no siempre se aterriza en la realidad, sino que las comunidades viven sus propias circunstancias.

En la comunidad de Pamatácuaro durante el periodo 1997-2000 se ejecutó un proyecto que daría inicio al aprovechamiento legal y colectivo de su territorio boscoso, pero fue un total fracaso. Desde entonces no ha existido algún otro intento por legalizar la explotación del bosque de coníferas y posiblemente no lo haya durante mucho tiempo. Quizás tendrán que pasar algunas generaciones más para que haya cambios, tal vez los jóvenes sean esas nuevas semillas de transformación y conservación, ya que en conversaciones con algunos de ellos parecen mostrar preocupación por conservar los árboles en el cerro grande, así nombrado el territorio, donde se localiza el bosque templado.

\section{Sistema de cargos y el bosque}

El sistema de cargos es una institución local en San Juan Pamatácuaro, se trata de una forma tradicional de organización social que hace hincapié en principios religiosos y que ocupa un lugar central en los grupos étnicos de México (Korsback 1996; Cancian 1976), tal es el caso de los p'urhepechas. Lo anterior, es la razón por la cual resulta indispensable hablar de ello, debido a que representa los intereses locales y relaciones sociales que cohesionan a la comunidad; la diferencia estriba en cuál es la estructura y cómo se asumen esos cargos en cada una de ellas. Encontramos que en Pamatácuaro es una forma de organización social en un ámbito meramente religioso, no civil.

La labor de sistema de cargos no trasciende en reglas ni acuerdos locales para la explotación del bosque, como en otras partes de la república mexicana, únicamente, se responsabilizan de organizar las fiestas religiosas sin realizar ningún otro tipo de actividad. Se puede mencionar el caso de San Pedro el Alto en Oaxaca, donde existe un sistema de cargos compuesto por alcalde, fiscal de iglesia y mayordomo que permite equilibrar no sólo las relaciones de poder -"hombres fuertes"-, sino que también funciona como una institución bajo el principio de "servicio a la comunidad", ha servido como mecanismo para que los comuneros realicen buen 
uso y manejo de su bosque de coníferas y, actualmente, sea una empresa forestal social comunitaria exitosa (Garibay, 2005). Cabe decir, que no hay fórmulas mágicas o recetas para consolidar una empresa social forestal, ya que entran en juego diferentes factores. No sólo interviene el interés económico, como lo señala Ostrom (2000) puede ser un mediador de organización, también depende de las condiciones propicias para que surja una movilización e iniciar un proyecto de empresa forestal comunitaria.

En Pamatácuaro, la asignación de carguero no es obligatoria y, generalmente es aceptada por el temor de recibir algún castigo divino en caso de ser rechazada; se percibe como un servicio que se ofrece a un santo, a quien se le tiene temor y mucho respeto, no siendo un servicio propiamente a la comunidad y no es remunerativo. La "fiesta grande" como ellos la llaman, es la que se celebra cada año en el tercer domingo del mes de julio; se trata de la fiesta patronal del Señor del Calvario. Los cargueros se encargan de contratar bandas de música de viento, de recabar cooperaciones para los gastos que sean necesarios en la fiesta, además de todo lo requerido para la verbena.

En la demarcación de las relaciones que se establecen entre sistema de cargos y el bosque templado, San José es el único vínculo que existe, ya que es el santo de los artesanos en el pueblo, porque se dice que él era de oficio carpintero. Su nicho se encuentra adornado con diferentes objetos de madera en miniatura (cucharitas, palitas, rodillitos, molinillitos, trasteros, canastitas, etc.). Además, sólo permanece un mes en la casa de quien lo recibe, motivo por el cual en el pueblo se le conoce como el "andariego", teniendo una rotación anual a diferencia de las demás imágenes religiosas.

\section{Comunidad agraria como organización social}

En México existe una tenencia de la tierra denominada: ejido y comunidad, misma que se regula en la Ley Agraria (sección 5, artículos 73 al 75; capítulo IV, artículos 93 al 97; capítulo V, artículo 98 al 107 en DOF, 1999). Dicha tenencia surge después de la revolución mexicana en 1910, la primera corresponde a poblaciones mestizas y la segunda a poblaciones indígenas, Pamatácuaro pertenece a esta última modalidad. Dicha ley prescribe a los ejidos/comunidades o núcleos agrarios como organización social para tomar decisiones y establecer acuerdos para la explotación de los recursos naturales contenidos en sus límites territoriales. 
Rigoberto Sandoval-Contreras. Territorio comunal: acuerdos locales para el aprovechamiento del bosque en la comunidad indígena de San Juan Pamatácuaro, México

También en el artículo 27 de la constitución política fracción VII que establece "se reconoce la personalidad jurídica de los núcleos de población ejidales y comunales y se protege su propiedad sobre la tierra, tanto para el asentamiento humano como para actividades productivas". Se reconoce la capacidad que tienen para adoptar las medidas que más convengan en el aprovechamiento de sus recursos productivos y regular sus derechos sobre la tierra y su parcela.

En el caso de Pamatácuaro, el régimen de propiedad comunal que oficialmente debe existir para usar el bosque en la práctica se caracteriza por una convergencia de formas de propiedad y no de una sola. El desfase que existe entre lo ideal y lo real es inevitable, no sólo en Pamatácuaro, las parcelas también las reconocen como pequeñas propiedades y ese es el sobrenombre que llevan "las pequeñas"; aunque jurídicamente no lo sean. Las formas de tenencia de la tierra pueden servir para entender cómo se regula y controla su acceso, pero limitarnos a ellas sólo nos aleja de la realidad como en el caso de estudio, pues es más complejo decir que se rige por una forma de tenencia comunal y enumerar los elementos que la definen según la Ley Agraria. Como comunidad indígena se esperaría que la explotación del bosque fuera en forma de organización colectiva, pero lo que se registra en la práctica es un aprovechamiento individual no colectivo.

Así pues, el territorio boscoso de Pamatácuaro se encuentra dividido en dos áreas, las parcelas localizadas en la periferia y el uso común, ubicado hacia el centro, pero ¿cómo se accede a una parte de territorio? Una manera de acceder a la tierra (parcela) en Pamatácuaro es por la herencia de padres a hijos. Cuando un comunero deja la comunidad con el paso del tiempo pierde sus derechos sobre la parcela, situación que raramente sucede, ya que siempre hay hijos a quien heredar. La parcelación del bosque ha contribuido a la diferenciación social enmarcada, principalmente, por el uso individualizado de la tierra. Esto limita la acción colectiva. Esta forma de apropiación en la práctica bien podría entenderse como una forma de propiedad particular, porque entre ellos mismos pueden vender libremente. Sin embargo, legalmente el bosque no está considerado como propiedad privada, como ya se dijo, es considerada como una propiedad social comunal por ser una comunidad indígena.

Una segunda modalidad, para acceder a la tierra, es mediante la apropiación de una parte del área de uso común, para lo cual puede o no 
pedir permiso a las autoridades comunales en turno, basta con que a un comunero le guste una porción de tierra y que ésta no tenga algún dueño, puede convertirse en el nuevo propietario, siendo así, sus colindantes se dan por enterados, sin más sólo empiezan a aceptar que ese pedazo de territorio ya pertenece a otra persona. Así lo confirma el testimonio de un comunero: "aquí cualquiera de la comunidad puede hacerse de una parcela, con sólo elegir un pedazo que le guste, puede hacerlo suyo si no es de nadie", esto es muy peculiar en Pamatácuaro. Para algunos académicos mexicanos resulta increíble y a decir verdad es algo que sorprende, sin embargo, así es como pasa, lo pudimos confirmar por observación directa en campo, comentarios vertidos en las entrevistas a profundidad realizada con algunos comuneros. "Ese terreno ya está sacado del mapa, ése ya no es de la comunidad. Ahí nadie puede aprovechar el recurso maderero, pero a veces unos se pasan de listos y si ven que el dueño anda tomado o que sale fuera" (Luis, artesano) ${ }^{4}$.

La tercera opción, consiste en la compra de una parcela, esto se realiza solamente entre los mismos comuneros, ya que no es permitido que individuos del exterior adquieran extensiones de tierra. En caso de que alguien quisiera hacerlo, tanto autoridades comunales como la mayoría de los comuneros se opondrían rotundamente a tal compraventa. De esta forma incluyen y excluyen, no permitiendo que nadie más entre a su territorio a extraer árboles ni comprar tierra. Estas tres formas de acceder a la tierra en Pamatácuaro son formas de organización agraria que caracterizan a sus acuerdos locales.

Por tratarse de una comunidad indígena podría suponerse que se tiene clara la idea de quién es un comunero y quién no lo es, la realidad es que la mayoría se autonombra así, comunero. Esta es una categoría que se asume tácitamente por el sólo hecho de vivir en territorio comunal, aunque también se identifican como campesinos porque viven en el campo. Se podría definir como comunero aquel que ha alcanzado la mayoría de edad, ya que son los adultos quienes participan en el uso del bosque y se les reconoce como dueños de parcelas. En este caso no hay que proporcionar algún servicio a la comunidad, tareas de faenas o que tengan que pasar por una serie de pruebas para alcanzar este reconocimiento como en otras comunidades indígenas del

4 Artesano, tiene 31 años y hace juguetes. Su papá se dedicaba a extraer resina. 
Rigoberto Sandoval-Contreras. Territorio comunal: acuerdos locales para el aprovechamiento del bosque en la comunidad indígena de San Juan Pamatácuaro, México

país. Pues en México hay casos que para ser comunero se deben hacer méritos para ser aceptados o rechazados (Garibay, 2005)

Ante la pregunta ¿usted es comunero? los artesanos entrevistados decían que eran comuneros porque viven ahí en "pama", "aquí todos somos comuneros". Nadie de los entrevistados se excluyó, aunque tuviesen una porción mínima de parcela o no tuviesen. Ningún comunero tiene claridad de las implicaciones legales que conlleva reconocerse así. El ser comunero en Pamatácuaro es solamente por el arraigo que existe al territorio, por residir en ese lugar, por haber nacido, crecido y reproducido ahí mismo. Basta que se reconozcan entre ellos mismos y participen de las actividades cotidianas: relaciones sociales de compadrazgos, amistades, fiestas y trabajos en conjunto como la construcción de la iglesia, actualmente.

Por pertenecer a la comunidad o ser originarios de la comunidad tienen el derecho de usar el bosque de coníferas y su contenido como: tierra, leña, hongos y plantas medicinales. Así también, tienen derecho a poseer una parcela; sus derechos y obligaciones se reconocen y se saben en un contexto local mediante los usos y costumbres.

En cuanto al número de comuneros totales, el programa de Certificación de Derechos Ejidales y Titulación de Solares (PROCEDE), puede ser un referente para saber con exactitud cuántos comuneros existen en la comunidad. Sin embargo, no fue posible llevar acabo su aplicación debido a los litigios que hay con sus colindantes, y un requisito para iniciar el PROCEDE es tener una delimitación precisa de extensión territorial. En su caso, las autoridades comunales no muestran algún interés por entrar a dicho programa o simplemente desconocen cuál es la manera en que opera el mismo. Según el Diario Oficial (1984), en Pamatácuaro como organización agraria se reconocen 1,608 , un número bastante considerado a otros núcleos agrarios que pueden ser de 30,60 o hasta 100 personas.

En Pamatácuaro como comunidad agraria, el comisariado comunal o representante de bienes comunales en los pueblos indígenas suele ser un elemento importante de organización social comunitaria. Es una institución que también se rige por normas y principios que legalmente se reconocen en la Ley Agraria y que en la comunidad se acepta su existencia y se respeta como autoridad.

El comisariado comunal se compone de presidente, secretario, tesorero y suplentes para cada cargo, luego está el consejo de vigilancia que 
también está integrado por tres comuneros, presidente, secretario y tesorero. Los integrantes elegidos se cambian cada tres años, para ello se hacen invitaciones por medio de los altavoces. Los candidatos, que generalmente, están afiliados a algún partido político -ya sea el Partido Revolucionario Institucional (PRI) o el Partido de la Revolución Democrática (PRD)-, empiezan a hacer reuniones por barrios o cuadras para presentarse. Cada partido tiene su propio candidato.

Los candidatos se promueven haciendo visitas a sus paisanos que viven en diferentes ciudades de la república mexicana como Guadalajara, Zamora, Monterrey, Los Reyes, Zacapu, Nueva Italia, entre otras. A quien se le promueve y privilegia con el voto es porque es trabajador, "sí le echa ganas", "no se emborracha", "es buena persona", "se les reconocen valores y compromiso". No obstante, la formación profesional ha sido fundamental en la elección de quien funge como representante, "se eligió un abogado porque toda la gente decía, él sí sabe, conoce de leyes, él sí puede defendernos bien de todo lo que pase en la comunidad, de los problemas que tenemos de litigio, los va a resolver bien, ya estudió, por eso hay que votar por él" (Luis, artesano).

El día de la elección del comisariado comunal se produce un espacio territorial enmarcado por las preferencias partidistas. De los que viven fuera, algunos vienen solo a votar ese día. Según los usos y costumbres en la comunidad el acuerdo es que "el voto no debe ser secreto", "la gente quiere ver con sus propios ojos", no quieren perder la tradición de los antepasados, por tanto, no quieren votos secretos. Para ello, se realizan dos filas en el centro del pueblo, hacia el norte se forman los que votan por el PRD y hacia el sur los que son partidarios del PRI. Naturalmente, hay posiciones encontradas, quienes están a favor y quienes en contra de que esto siga funcionando así. Por consiguiente, resulta la confrontación cara a cara y con esto se fomenta el divisionismo y la desintegración. "Nos formamos en fila, y yo creo que está mal eso; porque por ahí empieza la división, de que tú votaste por él y luego empiezan los problemas. ¿Mejor por qué no se piden casillas, y votamos así? No, pues no quieren. Hay unos que dicen que son del PRD y ahí empieza la discusión." (Luis, artesano). Esta división partidista ha trastocado diferentes espacios en las relaciones de los miembros de la comunidad, ya que en la actualidad es casi impensable emprender una forma de organización comunitaria sin que antes resurja su identificación ya sea con el PRI o con el PRD.

5 Los párrafos entrecomillados corresponden a los testimonios de los entrevistados 
Rigoberto Sandoval-Contreras. Territorio comunal: acuerdos locales para el aprovechamiento del bosque en la comunidad indígena de San Juan Pamatácuaro, México

Se produce un territorio en disputa por intereses políticos como lo analiza Manzano (2013). Este tipo de divisiones también afecta la acción colectiva.

Esta situación de apego a un partido político ha generado que los pamatacuareños socialicen en un modo peculiar, es decir, con mayor facilidad socializan si pertenecen al mismo partido, que con los "otros" oponentes, teniendo repercusiones en la familia, los barrios, el pueblo, relaciones de amistad, de compadrazgo y la explotación del bosque, ya que es impensable concebir su uso y manejo colectivo sin que antes allá una identificación partidista. El territorio de asentamientos humanos, -el pueblo- también está dividido en dos partes, del centro hacia el norte residen aquellos que tienen preferencias por el PRD, mientras los que habitan del centro hacia el sur apoyan al PRI. Incluso mencionan movilidad habitacional, pues hay casos de gente que se ha cambiado de residencia para no estar en donde viven los de un partido que no es de su preferencia ni de su interés.

Los comuneros consideran que sus autoridades tienen la responsabilidad de vigilar el territorio para que no invadan los colindantes, resolver conflictos territoriales, cuidar del bosque y vigilar que éste no se deteriore, ya que ellos están facultados para ejercer el poder y hacer todo tipo de gestiones y trámites que sean necesarios en pro de los mismos comuneros y su territorio. En parte sí son las funciones que realizan, si bien el comisariado comunal se le considera "cuidador del bosque", esta autoridad parece quedar desdibujada por la manera como los comuneros están haciendo uso de sus recursos madereros. Ni las autoridades ni nadie en la comunidad protestan o llama la atención por la extracción de madera del área de uso común o de sus propias parcelas, cada uno de los comuneros es libre de hacer lo que convenga a sus necesidades y propios intereses. En palabras de los comuneros al comisariado comunal se le confieren las siguientes funciones:

El comisariado comunal tiene la función de vigilar sobre la venta de tierras, dar legalidad a la venta de parcelas que existen en el monte, cuidar de que no se destruya el bosque, y a pesar de que ésta pueda ser una de sus funciones, mucho de este recurso sigue deteriorándose, ya que la mayoría de la población realiza trabajos relacionados con el uso de la madera, para hacer bateas, cucharas, juguetes, molinillos, tortilleras, etc. (Emiliano, profesionista) ${ }^{6}$

6 Emiliano tiene 32 años, es profesionista, ha sido autoridad de la comunidad. 
En México la Ley Agraria reconoce a las asambleas comunales como la máxima autoridad, ya que ahí se toman las decisiones y acuerdos que compete a la comunidad agraria. Pamatácuaro se caracteriza porque no hay asambleas frecuentes, sólo se realizan cada tres años cuando hay cambio de autoridades para informar los resultados, puede llegar a haber convocatoria en casos de emergencia como un problema de invasión de su territorio.

Por otro lado, la autoridad civil en la comunidad se denomina jefatura de tenencia, ésta se compone por un presidente (jefe de tenencia) y dos jueces, quienes participan de la conciliación de conflictos suscitados entre miembros de la comunidad y en casos de problemas conyugales, son los jueces o el primer juez quien atiende dichas situaciones. Algunos problemas más frecuentes que reconocen los jueces y artesanos, y que se presentan en la comunidad son los siguientes:

Los predios tienen todos sus escrituras, se hace un papel de compraventa, ante el juez menor de tenencia. Es quien se encarga de los conflictos, de conflictos con la gente ahí se arreglan, si se golpean, o si hay situaciones entre ellos. El jefe de tenencia también puede arreglar todos los conflictos. Sin necesidad del juez de tenencia (Everardo, artesano).

Efectivamente, tal como se menciona en el testimonio, así es como se desempeñan los jueces o jefe de tenencia en la comunidad, no teniendo incidencia sobre la apropiación del bosque en Pamatácuaro.

\section{Los acuerdos locales para la apropiación del bosque}

En Pamatácuaro existen pocas áreas destinadas al uso agrícola para la siembra de maíz o frijol, la mayor parte del territorio de la comunidad es de uso forestal 8,000 hectáreas de un total de 14,000 hectáreas (Carpeta Básica)7. Es así que el bosque más denso de pino, oyamel y encino se encuentra "allá en el cerro grande", como lo denominan los comuneros. Dicho espacio se encuentra fraccionado en dos partes: parcelas y área comunal. Las parcelas oscilan entre la media hectárea y un máximo de 17 hectáreas; generalmente se encuentran pobladas de pinos o encinos y ubicas alrededor del cerro grande, sobre todo en las orillas de él, mismas que se fueron formando de la periferia hacia

7 En México la carpeta básica es el archivo que ejidos y comunidades agrarias tienen en su disposición. 
Rigoberto Sandoval-Contreras. Territorio comunal: acuerdos locales para el aprovechamiento del bosque en la comunidad indígena de San Juan Pamatácuaro, México

el centro. En cuanto al área de uso común se localiza en la parte más céntrica de la extensión territorial boscosa.

No se puede hablar de un total de hectáreas parceladas, pues no existe delimitación perimetral y parcelación vigente que haya sido realizada por algún organismo especializado en la materia. Más bien, las delimitaciones internas entre espacios parcelarios y área de uso común son producto de compras y ventas de parcelas, cesión de derechos de padres e hijos y parcelación de la misma que únicamente los dueños conocen. Se podría decir que los dueños se rigen en aproximaciones. Aunque las autoridades entrevistadas y comentarios de algunos comuneros mencionan que serán un porcentaje de "cincuenta y cincuenta", es decir, que la mitad puede ser de uso común y la otra mitad son parcelas.

La parcelación del bosque ya tiene alrededor de tres generaciones establecidas después de que se dejó de extraer resina desde mediados de la década de 1970; en ese momento cada uno de los comuneros recibió un cuartel o parcela para que pudieran extraer esa sustancia orgánica, con el tiempo quedó el bosque parcelado. Desde entonces cada uno de los comuneros ha hecho uso de su parcela, enmarcando así la vida en la comunidad.

En el caso de Pamatácuaro el territorio es un espacio producto del trabajo que han invertido sus usufructuarios los comuneros. Bajo este preámbulo, podemos hablar de las parcelas como una manera de apropiación del territorio y una modalidad que es manifestación de la institucionalidad de acuerdos locales, éstos no se encuentran escritos, pero así funcionan en la práctica, rigen la conducta de los comuneros para usar y explotar su bosque y establecen dónde empieza una y dónde termina la otra. Se trata de modos de apropiación de los recursos forestales y formas de organización del territorio como un recurso, es decir, como un espacio de producción y reproducción social (Tomadoni, 2007), ya que haciendo un aprovechamiento del bosque se obtienen ingresos para el sustento de las familias campesinas de Pamatácuaro. La población es un elemento que de ninguna manera está separada del territorio, se hace visible por el trabajo humano y lo materializa (Lefebvre, 1974).

Los residentes en la comunidad entretejen una serie de relaciones sociales que dan vida a la existencia del pueblo, mismo que se encuentra establecido en un territorio y tiempo, en el cual se han ido creando espacios de convivencia y actividades productivas madereras. Entonces, puede 
verse el territorio de San Juan Pamatácuaro como un conjunto de procesos de construcción social en el que interactúan los comuneros y recursos forestales. Como lo plantea Cantera (et. al, 2001) y Jiménez (2011) el territorio también es un recurso patrimonial, destacando que la dimensión histórica, los símbolos (valores sociales, representaciones compartidas, instituciones locales) y la infraestructura constituyen la memoria colectiva en un ámbito local. Naturaleza y sociedad siempre vinculados, inseparables y cambiantes (Santos, 2000; Tomadoni, 2007).

Las parcelas están bien delimitadas por cercados de púas, ramas de árboles o postes, por riachuelos que se han ido formando por las lluvias. Algunas llegan a tener rejas para evitar su acceso, esta división del bosque no ha limitado el derecho de paso y la gente traza sus veredas acortando las distancias de un lugar a otro. En general, los comuneros son respetuosos de las parcelas al no extraer árboles que no son suyos a menos que los compren. El acuerdo local que prevalece es que por ninguna razón o motivo una persona ajena debe introducirse y saquear una parcela, sólo los dueños o propietarios explotan los árboles que ahí se encuentran.

Los artesanos consideran que cada uno "siempre" ha trabajado por su cuenta en su parcela o comprando algunos pinos para fabricar diversos objetos de madera. Más bien, quienes extraen de otras parcelas, son aquellos individuos de la comunidad que se dedican a cortar trozos de pino para venderlos a los aserraderos, y son quienes usan más cantidad de madera en comparación con los artesanos para la producción de cajas para embazar fruta.

En caso de que el dueño de la parcela decidiera hacer un cambio de uso de suelo, no se requiere de la aprobación de la asamblea comunal, de comuneros, ni autoridades comunales y mucho menos la de las autoridades civiles; se trata de un acuerdo local establecido que se ha conformado por la costumbre, por tanto, no es algo que se encuentre escrito. Si una parcela es vendida o algún comunero tuviera la intención de venderla a otro comunero, el acuerdo es que la venta sólo se realiza entre comuneros, nunca con otros individuos que no pertenezcan a la comunidad.

Cuando se vende una parcela los demás sólo se enteran, puede informarse o no a las autoridades comunales, ya que, generalmente, los tratos de compra venta son verbales y no necesariamente se requiere de un documento que avale tal práctica. Por tanto, entre los comuneros se reconoce muy bien quién es el dueño y ubican perfectamente su residencia en el pueblo. Esta 
Rigoberto Sandoval-Contreras. Territorio comunal: acuerdos locales para el aprovechamiento del bosque en la comunidad indígena de San Juan Pamatácuaro, México

situación no es más que la funcionalidad imperante que se rige por el uso normativo de usos y costumbres locales. Como lo sugiere Ostrom (2000) se trata de una institucionalidad local, con sus propias particularidades.

En caso de que el comunero desee hacer una tabla rasa de árboles en su parcela, nadie comenta nada, en la vida diaria se observa que eso no tiene que ser discutido con otro comunero y no es necesario dar parte a la autoridad comunal. Aunque la ley agraria establece que "en los casos en que no exista asignación de parcelas individuales se presumirán iguales, mientras no se pruebe lo contrario, los derechos correspondientes a los comuneros". Respecto a Pamatácuaro, no necesariamente hay asignación de parcelas, según los entrevistados, algunos toman su parcela sin notificar a las autoridades y sin pedirle permiso a nadie.

Ahora nomás van y agarran - un pedazo de tierra del área común- y ya no piden permiso a nadie. Ahora agarran hasta donde se les antoje; antes hubo más respeto. Hay gente que tiene diez hectáreas, les gustó o porque sus papás ahí trabajaban. Ya vieron para talar, por eso eligen tanto espacio, porque se tienen ganancias. De las parcelas se hacen minutas, documento que dice que es dueño, eso se hace con el juez menor. Sólo para los que venden, los que adquieren del uso común no tienen nada (jefe de tenencia)

Los acuerdos locales que regulan el área de uso común establecen que es un espacio de acceso abierto sólo para los miembros de la comunidad. Esta es una parte que se ha ido fraccionando poco a poco pero no totalmente, ya que aún existe un espacio que es considerado como abierto, en el pueden entrar libremente y extraer las unidades de recurso contenidas, siempre y cuando se siga siendo miembro de la comunidad, pues sólo así se tiene acceso a ella sin restricción alguna. Al igual que en las parcelas, el área de uso común se encuentra libre de agentes externos que se introduzcan para extraer los recursos maderables y no maderables existentes.

Tampoco se permitiría que alguien ajeno a la comunidad compre una parte del mismo. Aquí al igual que en el uso de las parcelas, las autoridades civiles y agrarias no restringen explotación alguna, sucede que hay individuos de la comunidad que se dedican a cortar los árboles de pino para venderlos en trozo o para ser utilizados en la elaboración de cucharas u otros objetos de madera. 
Del área común se ha sacado mucho, ya no tiene nada; es que de por sí varios extraen a cada rato, unos van con su burro o caballos y traen trozos de pino. Los cortan y los venden en trozos, o si no los agarran para hacer cucharas o juguetes, y es que aquí todavía habemos quienes hacemos juguetes, pero ya somos pocos. Unos decían, vamos para allá a la parcela y se iban y se iban, y traían pinos. Es un terreno grande, el que quería llegaba y cortaba árboles. Pero ya no hay mucho, porque el incendio los acabó. Pero ahí todo el que quiera puede ir y cortar los árboles y nadie le dice nada, que no lo haga porque es de la comunidad; si fuera parcela, ahí sólo el dueño los corta (Luis, artesano).

Una ventaja de estos acuerdos locales es que protegen sus propios recursos forestales para que agentes externos no puedan saquear su bosque, sin embargo, como nos hace reflexionar Ostrom (2000), sí representa un problema el hecho de que no se regule o controle el aprovechamiento del bosque de coníferas, en qué cantidad se debe extraer madera, dónde, cómo. Además, no existe un programa de manejo como tal que mitigue el efecto de su explotación y el aprovechamiento de las unidades de recurso como la extracción de leña y otros productos no maderables como los hongos, quelites o plantas medicinales como lo sugiere la Ley General de Desarrollo Forestal Sustentable (2003).

El acuerdo local que prevalece es el siguiente, si algún miembro de la comunidad al dirigirse a su parcela en su trayecto encuentra té de nurite, aunque no sea su terreno, con plena tranquilidad y seguridad de que no va a ser juzgado ni demandado, puede cortar algunas ramas o arrancar la planta para llevársela y plantarla en alguna parte de su espacio doméstico. También está permitido introducirse al bosque para realizar esas actividades. Así es como se da el uso y extracción de bosque templado en Pamatácuaro.

\section{Ley escrita y las otras (usos y costumbres)}

Hasta aquí hemos expuesto las premisas comunales, territoriales y culturales de cómo funciona la organización social de San Juan Pamatácuaro. Decíamos que los acuerdos locales son un sistema de reglas que se fundamentan en un marco normativo de usos y costumbres que se practican cotidianamente para apropiarse y extraer recurso del bosque. Es pertinente ampliar nuestro análisis sobre los conflictos que se suscitan al interior de la comunidad, por el saqueo de árboles en las parcelas, y de esa manera 
Rigoberto Sandoval-Contreras. Territorio comunal: acuerdos locales para el aprovechamiento del bosque en la comunidad indígena de San Juan Pamatácuaro, México

conocer su complejidad. No damos por hecho que la vida en la comunidad transcurre como un todo organizado y en orden por dichos acuerdos locales, lo que sucede es que la trascendencia de los conflictos puede ser considerados como de baja intensidad, ya que no llegan a trascender en confrontaciones violentas o muertes.

Quien puede ilustrarnos en una vertiente jurídica, social y cultural de cómo se norma la conducta en las comunidades indígenas de la sierra p'urhepecha y demás subregiones p'urhe en el Estado de Michoacán es Franco $(1997: 83)^{8}$, quien se ha encargado de esclarecer el binomio que hay entre la ley escrita y las otras. La primera, "procede de la ley escrita -legalmente reconocida e institucionalizada por el gobierno federal- y las otras, tienen su origen en la costumbre".

Así podríamos decir, que la vida de los hombres y mujeres en San Juan Pamatácuaro se encuentra en un marco de derechos y obligaciones que están lejos de ser alineados en un fundamento de bases legales, y no es que esté carente de leyes, simplemente son diferentes. Es precisamente la cultura la que nos adentra a la naturaleza humana, normas y directrices de una legislación meramente local, reacciones y respuestas que presentan la complejidad de la forma de vida de un grupo social en la sierra p'urhe.

La costumbre es una norma no escrita que usa la colectividad y es considerada como obligatoria. "La repetición de ciertas formas de comportamiento es razón de su validez específica y da origen a la idea de que aquello que siempre se ha hecho en determinada forma, debe hacerse siempre igual por ser un uso inveterado" (Franco, 1997: 84). Este análisis de la norma y su aplicación nos presenta la manera de cómo la cultura determina e incide en la vida que realiza el individuo. En este caso, la visión del indígena y la del "turhisi" (el que no es indígena) "es como si estuviera parado en un sitio donde convergen suelos de diversa consistencia, apoyando cada pie en terrenos diferentes, uno más movedizo que el otro y, por ende, sin encontrar pleno apoyo para sentirse completamente seguro" (Franco, 1997:137). Esta dualidad se manifiesta en la vida social de las comunidades y en la tenencia de la tierra y sus manifestaciones, ya que la tierra como objeto de apropiación implica dos vertientes: comunal y privada, entendiendo esta última como la forma de tenencia individualizada.

8 Moisés Franco Mendoza es Dr. y profesor-investigador del Centro de Estudio de las Tradiciones en el Colegio de Michoacán, A.C., originario de un pueblo de la Sierra Tarasca. 
Así pues, las leyes escritas chocan con la costumbre de los p'urhepechas no sólo en cuestión de tenencia de la tierra, sino en las relaciones sociales que se establecen y rompen con los parámetros legales establecidos fuera de su cultura. La aplicación de la justicia en su caso y sus mismas creencias son otras formas de organización social que funcionan en la vida diaria, regula y conduce la convivencia en la comunidad no sólo en los momentos de resolver los conflictos sobre el uso de la tenencia de la tierra, sino también en los ordinarios y familiares, "en lo que llaman "juchari irékakua" que significa nuestra forma de vida, nuestra convivencia, o simplemente nuestra costumbre que engloba los aspectos religioso, social, político y en general todo lo que pueda encaminar a la cooperación y solidaridad" (Franco, 1997:165).

Dichas costumbres no son más que normas sociales e instituciones que regulan el comportamiento de los individuos, que tienen un significado e inciden en su vida, ya que el proceso de socialización lo que hace es interiorizarlas, por tanto, trascienden en sus acciones y actitudes (Elster, 1995). Para el caso de Pamatácuaro, también se expresa en el uso parcelar y extracción de unidades de recurso. La costumbre es que los árboles no se pueden extraer de parcelas ajenas, pero hay situaciones en que los comuneros prefieren extraer los árboles de parcelas que no son suyas, en su intento de conservar el suyo o porque no tienen, aunque tampoco es una generalidad, porque implica hacer un plan de saqueo que debe realizarse en las noches o en días en que el dueño no está, o si se tratará de una parcela que parece estar abandonada, que el propietario o la propietaria sea una persona anciana que nunca hace recorridos por su parcela, aun en varios casos los hijos están fuera y cuando regresan se enteran de lo sucedido.

En caso de que haya una invasión por otro miembro de la comunidad, una vez que se entera el dueño puede o no repórtalo con la autoridad civil, concretamente con el juez civil o el jefe de bienes comunales. El infractor tiene que pagar el equivalente de lo que extrajo, o en su caso puede ser sancionado bajo la amenaza de ser encarcelado, pero esa es una situación poco probable, al parecer cada uno respeta lo que no es suyo:

Tengo dos pedacitos y ahí nomás me voy a dedicar ahí en la huerta y cuidar la madera. Ahorita ya comí, ya voy para allá, a los aguacates chaponearles y ahí donde están los árboles que ya están creciendo, ahí también voy. Una 
Rigoberto Sandoval-Contreras. Territorio comunal: acuerdos locales para el aprovechamiento del bosque en la comunidad indígena de San Juan Pamatácuaro, México

vez se llevaron todo, todo, y ya ahorita volvió a nacer, como nomás estaba mi mamá sola y ya está grande. Por eso andaban a gusto -los saqueadores-, y como nadie iba, por eso se llevaron todo. Toda la noche trabajan y ya al día se vienen. Uno tiene que estar pendiente de todo. Pero desde que regresé ya voy a dar mis vueltas. Unos sí tienen terreno, pero ya se acabaron lo suyo y empiezan a brincar a otros. Uno tiene que ir cualquier rato, un día en la mañana otro día en la tarde (Armando, artesano) ${ }^{9}$

Aun así, no existen casos registrados en los archivos de las autoridades comunales y civiles del pueblo en que se denuncien tales saqueos de madera en las parcelas. Aunque también los entrevistados aseguran que tales extracciones son situaciones que poco suceden, pues todos son respetuosos de dicho acuerdo no escrito. La invasión o saqueo tampoco es algo que lamenten cotidianamente o mencionen con frecuencia.

Las parcelas boscosas en la comunidad de San Juan Pamatácuaro parece que se encuentran en una situación de riesgo aceptado, pues no parece ser tan grave que los amantes de lo ajeno entren y se lleven los árboles; se puede afirmar que en cualquier situación que se presente existe una tolerancia al conflicto. Después de conocer el caso de un encuentro cara a cara entre el dueño de la parcela y usurpadores ¿qué más grave puede ser que un comunero enfrente una situación como esta? Aun así, no trasciende más allá de una simple discusión, molestia quizás, enfado de la víctima y por parte del invasor una justificación de su estancia por el predio, no aceptando y ni reconociendo la extracción de árboles, aunque las evidencias delaten la fechoría. En estas situaciones el acuerdo local puede establecerse ahí mismo, pactar una cantidad de pago por los árboles derribados, aunque como veremos a continuación en los términos del caso registrado no siempre se cumple tal cual lo negociado.

Yo tengo una parcela allá por las orillas del cerro que colinda ya casi muy pegado a las tierras de los vecinos de Zicuicho [...] Si hay árboles, pero no tantos, bueno, había más, pero un día que me di mí vuelta por ahí me encontré a unos tres fulanos que andaban por ahí, y ya estaban tirados los árboles, las ramas, todo. Y les digo: - ¿Qué andan haciendo por aquí? -

Dicen: -Pues nada, solo pasábamos por aquí; - ¿Ustedes son los que andan haciendo estas maldades verdad?; -No como crees, nosotros venimos a

9 Armando tiene 40 años, hace juguetes, prácticamente toda su vida ha estado trabajando fuera de la comunidad. 
buscar unos animales que no encontramos; -Pues si ya los tiraron, pues llévenselos, porque para que los van a dejar, se van a echar a perder, nomás hay me pagan algo de eso.

Pregunté: ¿Y usted no se enojó de eso?; -Pues como no me voy a enojar, pero ¿qué más hacia?, ya lo habían hecho, yo no podía traerme todo ese tiradero que hicieron ahí. Luego esas ramas se secan y al rato propagan los incendios, era mejor que se lo llevaran. Habían tirado como tres árboles, era mucho, yo y mis animales no podía sacar eso tan pronto, quien sabe cómo los sacarían ellos, a lo mejor era uno para cada uno. Y pues al final dijeron que si, que ellos lo hicieron y pues que hay me venían a pagar mis árboles, pero sólo uno de ellos me trajo como uno 600 pesos, pero los demás nunca vinieron.

Pregunté: ¿Y no los demandó o acusó con las autoridades comunales?; -Pues no, para qué, esto se arregla así, entre nosotros, no hay necesidad de hacer eso. Y pues son de la misma comunidad se puede arreglar. (Everardo, artesano $)^{10}$

Las varianzas que se suscitan por los casos de saqueo de árboles puede ser un detonador para producir conflictos; sin embargo, como hemos visto estos se caracterizan por ser de muy baja intensidad, no teniendo mayor trascendencia ni consecuencias graves o radicales. Los dos casos registrados nos dan muestra de la forma de proceder. Estos testimonios confirman lo que el Moisés Franco (1997) analiza en su estudio, la cultura es un elemento que influye para actuar o proceder de tal o cual manera en la cultura p'urhepecha, que sólo desde dentro puede entenderse, es decir, viviendo en la comunidad.

\section{Conclusiones}

Retomando algunos elementos teóricos de Ostrom (2000), podríamos decir que la comunidad de San Juan Pamatácuaro tiene linderos claramente definidos, es decir, su territorio se encuentra delimitado. Aunque tengan problemas de litigio, que se traduce en tensiones y conflictos con sus colindantes, el bosque se encuentra definido por las parcelas y el área de uso común. Cada uno de los comuneros tiene derecho a usar y explotar

10 Everardo tiene 43 años de edad, es artesano, hace tablitas y comercia molinillos, rodillos y tablitas de otros artesanos. Tiene una parcela que le cedió a un cuñado; desde hace más de 10 años se dedica al comercio y radica en Guadalajara. A cambio de la parcela le da una módica cantidad para su usufructo. 
Rigoberto Sandoval-Contreras. Territorio comunal: acuerdos locales para el aprovechamiento del bosque en la comunidad indígena de San Juan Pamatácuaro, México

su parcela, mientras que en el espacio común los derechos son de acceso abierto, pero los mismos comuneros lo aprovechan de manera clandestina.

En cuanto a la congruencia de reglas de apropiación locales, los acuerdos existentes no permiten el saqueo del bosque por agentes externos, eso puede ser una ventaja para su conservación porque ayuda a controlar el clandestinaje forestal externo. Aunque al interior de la comunidad, el uso del bosque sin permisos legales podría considerarse como una situación de clandestinaje, por otro lado, es una desventaja en tanto no se regule en qué cantidad se extrae el recurso forestal, de tal manera que éste se conserve y no se deteriore. La alta migración nacional que existe en la comunidad es también una manera de disminuir la presión sobre el bosque.

Sobre arreglos de decisión colectiva, los comuneros en sus prácticas diarias han establecido acuerdos locales para apropiarse del bosque, mismos que son aceptados por todos y respetados. Éstos se determinan como un sistema normativo de usos y costumbres que regulan y rigen la conducta de los comuneros. Las leyes oficiales que regulan el uso del bosque parecen no tener ninguna influencia en la manera de apropiar y extraer cada unidad de recurso contenida, tampoco las autoridades civiles locales o municipales.

Al interior de la comunidad no se requiere vigilar quién o quiénes están faltando a los acuerdos locales existentes para hacer un uso de sus parcelas o del área de uso común; se autorregulan y las autoridades externas municipales, estatales y federales tampoco realizan monitoreos, es decir, su explotación no es legal, según la Ley Forestal.

No existen fuentes documentadas de haber aplicado sanciones a alguien por incumplimiento de los acuerdos locales, aunque según fuentes orales si alguien extrae algún recurso maderable de otra parcela debe pagarlo. No hay antecedentes de que la comunidad haya recibido sanciones por incumplimiento a lo que marca la Ley Forestal.

Se establecen relaciones de confianza y existe la apertura para resolver los problemas que se puedan presentar por hacer uso del bosque, como la invasión de su predio o saqueo de recursos, obviamente, por los mismos comuneros, no por agentes externos, ya que las relaciones sociales que se establecen se fundamentan en costumbres propias de su identidad étnica. El sistema de cargos que prevalece en la comunidad no tiene incidencia para que se dé una explotación del bosque de manera colectiva. 
Existe el antecedente de una experiencia de organización previa de manera colectiva, para que el aprovechamiento de sus recursos forestales fuera regulado legalmente, sólo que fue apenas un acercamiento a la organización comunitaria, pues sólo duró lo que fue la administración del presidente de bienes comunales 1997-2000. Fue un rotundo fracaso.

Desde una perspectiva analítica desde Olson (1998) la comunidad de San Juan Pamatácuaro, es un grupo grande (más de 1000 comuneros), por tanto, es difícil de coordinar, se pierde el control de participación y negociación lo que conduce a una desunión, aunque existen casos aparentemente exitosos que si han sabido lidiar con estos detalles.

La formación de grupos mediados por intereses económicos y partidistas hace imposible una negociación trascendental para la creación de una empresa forestal comunitaria en acción colectiva, por eso los comuneros suelen actuar de manera egoísta e irracional. Haciendo un análisis de costos y beneficios, aceptar la compra de árboles individualmente o ceder sus derechos parcelarios para la conformación de una empresa forestal comunitaria, lo consideran poco adecuado y beneficioso a sus intereses individuales.

La asamblea comunal como máxima autoridad, no tiene las restricciones pertinentes que encuadren los comportamientos y actitudes para iniciar proyectos colectivos e incentivos colectivos. Una vez que se echó andar el proyecto de aserrado en Pamatácuaro, los comuneros no supieron crear los estímulos pertinentes para fomentar la integración y participación ni de los trabajadores dentro del aserradero ni de ellos mismos.

Desde los planteamientos teóricos de Elster (1995), los deseos $y$ oportunidades, los comuneros desearon tener ingresos y vieron la oportunidad de impulsar un proyecto colectivo, pero después de hacer una elección racional consideraron no participar, pues como seres humanos de carne y hueso se conducen en acción racional de acuerdo a su propia valoración de sus deseos, oportunidades, creencias, costos y beneficios; no consideraron beneficioso emprender un proyecto forestal administrado colectivamente.

No hay normas sociales que restrinjan la conducta del comunero y que lo someta a participar colectivamente, más bien las normas sociales que parecen regir las conductas de los pamatacuareños "son otras". Como lo sugiere Franco (1997), el uso y la costumbre tiene otro proceder en sus reacciones y prácticas, aunque tampoco implementan motivaciones de 
Rigoberto Sandoval-Contreras. Territorio comunal: acuerdos locales para el aprovechamiento del bosque en la comunidad indígena de San Juan Pamatácuaro, México

participación e integración; al ser un grupo grande se producen divisiones creando subgrupos lo que hace más difícil una negociación prudente.

Se concluye, que los comuneros de San Juan Pamatácuaro de la sierra p'urhe, producen reglas y normas que conducen su comportamiento de acuerdo con las situaciones vividas que las institucionalizan. En el caso del uso del recurso forestal son las "otras", la costumbre. No es que cada uno haga lo que quiere, se trata de normas o prácticas culturales que se entienden y se explican sólo en su propia cultura, desde dentro. Para los que no nacimos y vivimos ahí, nos puede parecer que es una total anarquía, sin reglas ni restricciones; sin embargo, hay acuerdos locales que norman la extracción de árboles y la misma división de su territorio, los asentamientos humanos y organización social.

\section{Referencias}

Altschuler, B. (2008). Repensando el desarrollo. Aportes y limitaciones del desarrollo local y la economía social a una estrategia de desarro1lo. En Martínez Valle, Luciano (Compilador) Territorio en mutación: repensando el desarrollo desde lo local, (pp. 29-46) Ecuador: FLACSO. Recuperado de http://www.flacsoandes.edu.ec/libros?ava nzado $=0 \&$ query $=$ Territorios + en + mutaci $\% \mathrm{C} 3 \% \mathrm{~B} 3 \mathrm{n} \% 3 \mathrm{~A}+$ Repensan do + el + desarrollo ++ desde + lo + local +

Amerlinck, M. J. y Bontempo, F. (1994). El entorno construido y la antropología. Introducción a su estudio interdisciplinar, México: CIESAS.

Cancian, F. (1976). Economía y prestigio en una comunidad maya: el sistema religioso de cargos en Zinacantán, Celia Paschero (trad.), México: INI/SEP,

Cantero, P., Escalera, J., García del Villar, R. y Hernández, M. (2001). Territorio, sociabilidad y valor patrimonial del espacio urbano. Usos sociales del espacio público en el casco histórico de Sevilla. Recuperado de http://www.euskomedia.org/PDFAnlt/zainak/19/19125140.pdf

Cernea, M. (1995). Primero la gente. Variables sociológicas en el desarrollo rural, México: FCE.

Diario Oficial de la Federación. (1999). Ley Agraria, México: Diario Oficial. 
Diario Oficial de la Federación. (2003). Ley General de Desarrollo Forestal Sustentable, México.

Elster, J. (1995). Tuercas y tornillos. Una introducción de las ciencias sociales, Traducción, Antonio Bonano, Barcelona: Gedisa,

Garibay, C. (2005). La transformación del comunalismo forestal: Identidad comunitaria, empresa social y poder corporado en el México contemporáneo, (Tesis de Doctorado en Antropología Social), Guadalajara: CIESAS Occidente.

Franco, M. (1997). La ley y la costumbre en la cañada de los once pueblos, El Colegio de Michoacán, A.C. Zamora Michoacán

Manzano, B. (2013). Territorios: teoría y disputas por el desarrollo local, pp.116-133). Recuperado de http://www.cedem.uh.cu/sites/default/ files/116-133.pdf

Lefebvre, H. (1974). La producción del espacio. En Revista de sociología. 3 219-229. Recuperado de https://crucecontemporaneo.files.wordpress.com/2011/11/1c2ba-47404221-lefebvre-henri-la-producciondel-espacio.pdf

Jiménez, L. (Dir.) (2011). Patrimonio natural, cultural y paisajístico. Claves para la sostenibilidad territorial. España: Universidad de Alcalá. Recuperado de http://www.upv.es/contenidos/CAMUNISO/info/ U0556177.pdf

Korsbaek, L. (1996). Introducción al sistema de cargos, Toluca, Edo. de México: UAEM.

Leff, E. (1998). Saber ambiental: sustentabilidad, racionalidad, complejidad, poder, México: Siglo XXI

Leff, E. (1995). Sobre la apropiación social de la naturaleza. En López Ramírez, Alfonso y Fernández, Pedro (coords.), Sociedad y medio ambiente: Contribuciones a la sociología ambiental en América Latina, Asociación Latinoamericana de Sociología, Universidad de Puebla, México.

Martín, A. (2001). Procesos de lucha y arreglos institucionales. El manejo forestal en la reserva de la biosfera mariposa monarca, (Tesis de Maestría, El Colegio de Michoacán), Zamora, Michoacán.

Olson, M. (1998). La lógica de la acción colectiva, México: Limusa-noriega. Ostrom, E. (2000). El gobierno de los bienes comunes: la evolución de las instituciones de acción colectiva, México: CRIM/EFE/UNAM 
Rigoberto Sandoval-Contreras. Territorio comunal: acuerdos locales para el aprovechamiento del bosque en la comunidad indígena de San Juan Pamatácuaro, México

Rodríguez, R. y Saavedra de la Cruz, G. (2012). La participación social en el ordenamiento territorial. Participación o representación un dilema legal y metodológico. En Aguilar Robledo, Miguel, et al., Ordenamiento territorial y participación social: problemas y posibilidades, México: INECC. 53-65. Recuperado de http://www.redalyc.org/articulo.oa? id=169419796004

Samper, M. (2013). Construyendo territorios participativos: sistematización de experiencias de desarrollo rural territorial en el centro de América, Costa Rica: ACIDCAC/IICA.

Santos, M. (2000). La naturaleza del espacio. Técnica y tiempo. Razón y emoción. México: Ariel, Recuperado de https://geografiacriticaecuador.files.wordpress.com/2013/01/santos-la-naturaleza-del-espacio.pdf

Secretaría de Recursos Hidráulicos (1986). Ley Forestal, México: Congreso de la Unión.

Tomadoni, C. (2007). A propósito de las nociones del espacio y territorio. En Gestión y Ambiente.10(1)

The Natural Conservancy (2007). Convention on biological diversity, Recuperado de https://www.cbd.int/protected-old/gap.shtml 
